\title{
Role of Magnetic Resonance Spectroscopic Imaging in Recategorization of BIRADS 4 Breast Lesions
}

\author{
DALIA BAYOUMI, M.D.*; MONA ZAKY, M.D.*; AHMED ABDALLAH, M.D.** and \\ DINA ABDALLAH IBRAHIM, M.D.*** \\ The Departments of Radio-Diagnosis*, Surgical Oncology** and Pathology***, Faculty of Medicine, Mansoura University
}

\begin{abstract}
Background: Breast cancer is one of the major causes of death among females, its early diagnosis allow better prognosis and prolonged survival rates of the patients. Post contrast dynamic MRI is the most sensitive method for breast cancer detection which has also good diagnostic performance for evaluation of different breast pathological lesions. Magnetic Resonance (MR) spectroscopy is a functional MRI technique which is used to study the metabolic profile of different breast lesions to improve the diagnostic accuracy of MRI especially in BIRADS 4 breast lesions in order to reduce the unnecessary biopsies.
\end{abstract}

Aim of Study: Evaluation of the role of multi-voxel MR spectroscopy in the recategorization of BIRADS 4 breast lesions when combined with Dynamic Contrast-Enhanced Magnetic Resonance Imaging (DCE-MRI).

Material and Methods: This study included 63 patients, their ages ranged from 28 to 73 years old with mean age 46.7 years old. All the patients included in this study were subjected to history, clinical examination, MRI examination and histopathology. Initially the included breast lesions were categorized as BIRADS 4 by conventional post contrast dynamic MRI techniques, and then we added the results of the magnetic resonance spectroscopic imaging to detect whether the spectroscopic data can improve the diagnostic accuracy of the MRI study. Finally the reported diagnosis was confirmed by histopathological specimens obtained after excision biopsy and core needle biopsy. We used 1.5 T MRI system and the sequences performed included T1 \& T2 pulse sequences, STIR and dynamic contrast enhanced MRI followed by MRS for the suspected lesions. For statistical analysis we used Ttest and ROC curve.

Results: This study included 63 female patients, their ages ranged from 28 to 73 years old with mean age 46.7 years old. All the breast lesion were categorized as BI-RADS 4 breast lesions based on the Dynamic Contrast-Enhanced Magnetic Resonance Imaging (DCE-MRI) then after magnetic resonance spectroscopy the breast lesions were re-categorized into BIRADS 3, 4 and 5 categories. Finally the results were compared to the histopathological results. The most common clinical presentation is palpable mass. We had 33 pathologically

Correspondence to: Dr. Dalia Bayoumi, The Department of Radio-Diagnosis, Faculty of Medicine, Mansoura University proven benign lesions and 30 pathologically proven malignant lesions. The diagnosis was downgraded into BIRADS 3 in 29 cases and upgraded into BIRADS 5 in 28 cases and in 6 cases there was no change in the BIRADS 4 categorization after MRS. During MRS examination the choline resonance peak was detected at a frequency of $3.23 \mathrm{ppm}$, and the choline SNR was measured at cut off value of 2 . There were statistically significant differences between malignant and benign breast lesions, the choline SNR measured $6.31 \pm 0.99$ (mean \pm SD) in the malignant lesions and it measured $1.902 \pm 0.47$ (mean \pm SD) in the benign lesions. The sensitivity, specificity, PPV, NPV and accuracy measured $81.3 \%, 62.6 \%, 76.5 \%, 67.1 \%$ and $73.4 \%$ for the DCE-MRI and measured $87.9 \%, 89.1 \%$, $85.2 \%, 88.9 \%$ and $94.8 \%$ for combined assessment by MRS and DCE-MRI.

Conclusion: Magnetic resonance spectroscopic imaging can be problem solving method for BIRADS 4 breast lesions when combined with dynamic contrast enhanced MRI to improve its diagnostic accuracy.

Key Words: Dynamic MRI of the breast-Magnetic resonance spectroscopy-BIRADS 4 breast lesions.

\section{Introduction}

BREAST cancer is one of the leading causes of death in females worldwide. It is a multifaceted and heterogeneous disease that shows various clinical challenges, especially in terms of diagnosis and assessment of response following different types of treatment planes used for management of the disease [1]

Dynamic Contrast-Enhanced Magnetic Resonance Imaging (DCE-MRI) plays a major role in the evaluation of different breast pathological lesions. Compared with conventional imaging techniques, DCE-MRI is considered the most sensitive method for the detection of breast cancer, with a negative predictive value up to $81-99 \%$ [2]

Also Magnetic Resonance Imaging (MRI) has gained wide approval because of its high sensitivity and moderate specificity ( $85 \%)$ as demonstrated 
by multi-centre trials, however, there is some overlap between benign and malignant diseases on few occasions, making the diagnosis relatively difficult on the basis of conventional MRI techniques alone [3]

One of the most important functional MRI techniques which showed comprehensive values in high lighting the metabolic activity of active malignant tumors all over the body is the in vivo proton Magnetic Resonance (MR) spectroscopy. It is a non-invasive imaging technique that can be effectively used for the assessment of breast lesions and for the evaluation of therapeutic response of the disease. The diagnostic idea behind MR spectroscopy depends on its ability to detect the elevation of choline-containing compounds (Cho) levels which are used as markers for active malignant tumors of the breast [4]

MR spectroscopy can be done by the singlevoxel or the multi-voxel techniques. The singlevoxel method has major drawbacks which are; its restricted coverage of the lesion of interest and its limited ability to represent the whole lesion in one voxel especially in heterogeneous tumors with heterogeneous tissue composition [5]

The other popular spectroscopic imaging method is the multi-voxel MR spectroscopy, which is also known as the chemical shift imaging. This method gives spectroscopic data from multiple voxels covering larger area of tumor tissue. So, this method can be more appropriate for investigating the distribution of the regional tumoral metabolites and learning more about the heterogeneity of tumor tissues [6].

\section{We aimed in this study:}

To evaluate of the role of multi-voxel MR spectroscopy in the recategorization of BIRADS 4 breast lesions when combined with Dynamic Contrast-Enhanced Magnetic Resonance Imaging (DCE-MRI).

\section{Patients and Methods}

This study is a prospective study which was conducted in the Radiology Department of Mansoura University Hospital over the period from February 2017 to December 2018.

This study included 63 female patients, their ages ranged from 28 to 73 years old with mean age 46.7 years old. All patients were referred from oncology Center of Mansoura University and outpatient surgery clinics.
The study was approved by our institution's ethics committee, and all patients gave their informed consent before inclusion in the study.

\section{Inclusion criteria:}

Female patients with breast lesion sized $\geq 10 \mathrm{~mm}$ which is categorized as BIRADS 4 by dynamic contrast enhanced MRI.

\section{Exclusion criteria:}

-Un-cooperative patients.

- Patients with metallic pace maker and ferromagnetic foreign bodies (contraindication for MRI).

- Patients suffering from claustrophobia.

- Breast lesion $<10 \mathrm{~mm}$ in size.

All the patients underwent the following:

I- Full history (at both Oncology Center and Radiology Departments) including:

- Onset, course and duration of the present illness.

- Past history of previous breast mass or mastectomy.

- Family history of breast cancer.

- History of previous radiological examination.

- Local breast and axillary lymph nodes examination.

The patients in our study had variable clinical presentations as shown in (Table 1); 27 patients presented with palpable breast swelling, 12 patients presented by nipple discharge, 10 patients presented with inflammatory symptoms, 8 patients presented with mastalgia and 6 patients came for postoperative follow-up.

Table (1): Showing the clinical presentations of the patients.

\begin{tabular}{lc}
\hline Mammographic findings & Number \\
\hline Palpable mass & 27 \\
Nipple discharge & 12 \\
Inflammatory symptoms & 10 \\
Mastalgia & 8 \\
Post-operative follow-up & 6 \\
\hline
\end{tabular}

II- Clinical examination (done by the referring physician) including:

- Local breast examination.

- Axillary lymph nodes examination.

III- Radiological investigation: The MRI examinations were done before breast biopsy or at least 7 days after biopsy, to avoid edema and hemorrhage. 
Magnetic Resonance Imaging (MRI):

Patient's preparations:

1- Before entering the examination room, the patients were instructed to remove all metallic objects and all clothes containing metal.

2- The patients were informed about the examination time and the value of remaining stable without motion during examination.

\section{Position:}

The patient was placed into the scanner in the prone position. The breasts were gently cushioned inside dedicated breast coil to reduce motion.

\section{Image acquisition:}

A- Localizing sagittal protocol (scout view).

$B-T 1$ and T2 weighted pulse sequence: Axial nonfat saturated TIWI was obtained by FSE with the following imaging parameters: TR $512 \mathrm{~ms}$, TE $8 \mathrm{~ms}$, slice thickness $3 \mathrm{~mm}$, Field of View (FOV) 400-500mm and matrix was $256 \mathrm{X} 256$. T2 W sequence (TR 2000ms, TE $8 \mathrm{~ms}$ ) axial section, STIR (TR 4000ms, TE 70ms \& inversion time (TI) was $175 \mathrm{~ms}$ ).

$C$ - Short TI inversion recovery (STIR): STIR was obtained with the following parameters: TR $4000 \mathrm{~ms}$, TE $70 \mathrm{~ms} \&$ inversion time (TI) was $175 \mathrm{~ms}$, slice thickness was $3 \mathrm{~mm}$ with inter slice gap $1 \mathrm{~mm}$, Field of View (FOV) 400-500mm and the matrix was $256 \mathrm{X} 256$.

D- For dynamic contrast enhanced MRI: All dynamic studies were made in the axial plane with fat suppression by applying fat saturated pulse. The sequence used was FLASH 3D GRE-T1W1 with the following parameters: TR 3-4ms, TE $1.5 \mathrm{~ms}$, flip angle 10 degrees, slice thickness $2 \mathrm{~mm}$ with no inter-slice gap, Field of View (FOV) $450 \mathrm{~mm}$ and the matrix was $256 \mathrm{X} 256$.

Dynamic study included one pre contrast and 5 post contrast series, the time of each of them was about $1.16 \mathrm{~min}$ with a break between the pre contrast and post contrast study about $20 \mathrm{sec}$.

After the pre contrast study, a bolus of gadopentate dimeglumine, in a dose of $0.2 \mathrm{mmol} / \mathrm{kg}$ was injected using an automated injector at a rate of $3-5 \mathrm{ml} / \mathrm{sec}$ through a $18-20$ gauge intravenous cannula inserted in an antecubital vein. This was followed by a bolus injection of saline (total of $20 \mathrm{ml}$ at $3-5 \mathrm{ml} / \mathrm{sec}$ ).

The phase-encoding direction was oriented to minimize motion artifacts across breast tissue, especially those from cardiac and respiratory motion. For trans-axial imaging, this means orienting phase-encoding to be from right to left.

\section{Kinetic curves:}

The ROI was placed carefully within the most enhancing part of the lesion. The size of the ROIs that were chosen in a lesion varied with the size and the shape of the lesion. When considerable heterogeneity in enhancement pattern was observed, multiple ROIs were used and the most enhancing areas were chosen for the analysis.

Time to signal intensity curve for each ROI was obtained. The horizontal axis of the curve represented the series number or time and the vertical axis represented signal intensity that was automatically calibrated by the machine according to the SI (enhancement) of the lesion.

E- For MR spectroscopy: Multi-Voxel Spectroscopy (MVS) examination was done for all of the patients. Proton MRSI was performed on a single 10-mm-thick sagittal section using a Point Resolved Spectroscopy Sequence (PRESS) with water + lipid suppression. MRS parameters were TR/TE $2000 \mathrm{~m} . \mathrm{sec} / 272 \mathrm{~m} . \mathrm{sec}$; matrix size $18 \mathrm{X}$ $18 ; \mathrm{FOV}=18 \mathrm{~cm}$; and total data acquisition time was approximately 12 minutes.

The time domain signal intensity was processed to remove the residual water signal. Post processing of the spectroscopic data consists of frequency shift and phase and linear baseline corrections after fourier transformation. Frequency domain curve was fitted to Gaussian line shape by using the software provided by the manufacturer to define choline-containing compounds (Cho) peak.

\section{Image post-processing:}

A- Image subtraction: Image subtraction was obtained by subtracting each of pre-contrast images from each post-contrast series images.

The following instructions should be considered:

- No motion between pre and post contrast scans.

- Displaying the subtracted images with the same window widths and window levels.

$B$ - Creation of time to signal intensity curves: Time enhancement curves were done for all patients.

$C$ - Maximum Intensity Projection (MIP): The MIP views were obtained through each orthogonal plane, producing sagittal, coronal and axial projections. 


\section{Morphological analysis:}

As our study was carried on inclusion criteria of breast masses as we excluded breast lesions described $<10 \mathrm{~mm}$ in size. A mass is a threedimensional space-occupying lesion measuring $\geq 10 \mathrm{~mm}$. It is usually visible on pre-contrast $\mathrm{T} 1$ or T2 weighted images. Masses are described in terms of shape, margin, and internal enhancement characteristics according to BIRADS-MRI lexicon.

\section{Analysis of enhancement kinetics:}

Considering the contrast enhancement pattern during the dynamic series, three different phases were distinguished:

1- The early phase (between contrast injection and the second post contrast minute).

2- The post initial phase ( 3 rd to 4 th post contrast minute).

3- The late phase (later than the 4 th post contrast minute).

The curves were classified into type 1 (persistent dynamic curve), type 2 (plateau dynamic curve), and type 3 (washout dynamic curve) curves.

\section{Analysis of MRS data and spectrum:}

We measured the Cho peak from the water suppressed spectrum using a narrow frequency range (e.g., 2.92-3.52ppm), the choline peak was considered positive if present at $3.23 \mathrm{ppm}$ and negative if absent. Then we analyzed the choline peak to quantify its amplitude in order to measure the choline SNR (signal to noise ratio), this ratio represent the amplitude of the choline peak to the amplitude of the noise and it is one of the most reliably used quantitative biomarkers.

\section{Statistical analysis:}

Descriptive data:

Descriptive statistical data were calculated for the anthropometric measurements and laboratory data in the form of:

- Mean \pm Standard Deviation (SD) for quantitative data.

- Frequency (number and percent) for qualitative data.

\section{Analytical statistics:}

The inter-group comparison of categorical data was done by using the chi square test ( $\chi^{2}$-value).

The sensitivity, specificity, positive predictive value, negative predictive value and accuracy were detected for MRI and MRS. Receiver-Operating Characteristic (ROC) curves were constructed for these parameters and the Areas Under the Curve (AUC) values were determined.

The $p$-value $<0.05$ was considered statistically significant. And the $p$-value $<0.0001$ was considered highly significant in all analyses.

\section{Results}

This study included 63 patients, their ages ranged from 28 to 73 years old with mean age was 46.7 years old. All the breast lesion were categorized as BI-RADS 4 breast lesions based on the Dynamic Contrast-Enhanced Magnetic Resonance Imaging (DCE-MRI) then after magnetic resonance spectroscopy the breast lesions were re-categorized into BIRADS 3, 4 and 5 categories. Finally the results were compared to the histopathological results.

The histopathological results are shown in (Table 2) as following; 30 pathologically proven malignant lesions ( 9 cases of ductal carcinoma in situ, 16 cases of invasive ductal carcinoma, 3 cases of invasive lobular carcinoma, 1 case of mucinous carcinoma and 1 case of local tumour recurrence) and 33 pathologically proven benign lesions (16 cases of fibroadenomas, 5 cases of Fibroadenosis with apocrine metaplasia, 2 cases of granulomatous mastitis, 7 cases of post-operative changes, 2 cases of inflammatory changes, 1 case of sclerosing adenosis).

Table (2): Showing the histo-pathological analysis of the lesions.

\begin{tabular}{ll}
\hline Histopathological analysis & Number of lesions \\
\hline - Fibroadenoma. & 16 \\
- Fibroadenosis with apocrine metaplasia. & 5 \\
- Granulomatous mastitis. & 2 \\
- Post-operative changes (fibrosis and trau- & 7 \\
matic fat necrosis). & \\
- Inflammatory hyperplastic changes with- & 2 \\
out atypia. & 1 \\
- Sclerosing adenosis. & 9 \\
- Ductal carcinoma in-situ. & 16 \\
- Invasive ductal carcinoma. & 3 \\
- Invasive lobular carcinoma. & 1 \\
- Mucinous carcinoma. & 1 \\
- Local tumour recurrence. &
\end{tabular}

As regards the BIRADS recategorization of the lesions as shown in (Table 3), we had 29 cases diagnosed as BIRADS 3 all of them were pathologically proven benign lesions, 6 cases diagnosed as BIRADS 4 (4 cases were confirmed benign and 2 cases were confirmed malignant) and 28 cases diagnosed as BIRADS 5 all of them were pathologically proven malignant lesions. 
Table (3): Showing the BIRADS categories of the lesions after combining the results of MRS with DCEMRI in relation to the final histopathological results.

\begin{tabular}{|c|c|c|c|}
\hline \multirow{2}{*}{ BIRADS category } & \multicolumn{2}{|c|}{ Pathology } & \multirow{2}{*}{$\begin{array}{l}\text { Chi-Square } \\
\text { test }\end{array}$} \\
\hline & Benign & Malignant & \\
\hline $\begin{array}{l}\text { - } \text { BIRADS-3 } \\
\text { category }(\mathrm{N}=29)\end{array}$ & $29(86.2 \%)$ & $\begin{array}{ll}0 & (0.0)\end{array}$ & $\begin{array}{l}\chi^{2}=19.36 \\
p<0.005\end{array}$ \\
\hline $\begin{array}{l}\text { - BIRADS-4 } \\
\text { category }(\mathrm{N}=6)\end{array}$ & $4 \quad(13.79 \%)$ & $2 \quad(7.14 \%)$ & \\
\hline $\begin{array}{l}\text { - } \text { BIRADS-5 } \\
\text { category }(\mathrm{N}=28)\end{array}$ & $\begin{array}{ll}0 & (0.0)\end{array}$ & $28(92.85 \%)$ & \\
\hline
\end{tabular}

By Dynamic Contrast-Enhanced Magnetic Resonance Imaging (DCE-MRI) the lesions were classified into mass lesions and non-mass lesions as shown in (Table 4). We had 29 circumscribed mass lesions, 15 non circumscribed mass lesions, 19 non mass lesions, 10 of them showed segmental distribution and 9 showed non segmental distribution.

Table (4): Showing the MRI appearance of the lesions.

\begin{tabular}{lc}
\hline MRI appearance & Number \\
\hline Mass lesions: & \\
Circumscribed mass & 29 \\
Non-circumscribed mass & 15 \\
Non-mass lesions: & \\
Segmental distribution & 10 \\
Non-segmental distribution & 9 \\
\hline
\end{tabular}

During the MRS examination the choline resonance peak was detected at a frequency of 3.23 $\mathrm{ppm}$. After the detection of choline peak the choline SNR was measured, this ratio represents the ratio of the amplitude of the choline peak to the amplitude of the noise. The choline peak was notable in all the pathologically proven malignant lesions with the choline SNR measured $6.31 \pm 0.99$ (mean $\pm \mathrm{SD})$.

While in the pathologically proven benign lesions the choline peak was not detectable or the
Choline SNR measured 1.902 \pm 0.47 (mean \pm SD). The cut-off value used to differentiate between benign and malignant breast benign lesions was 2 , at this cut off value we had the best diagnostic performance of Cho SNR to differentiate between benign and malignant lesions as shown in Fig. (1) and (Table 6).

Table (5): Showing the choline SNR differences between benign and malignant lesion in relation to histopathological results.

\begin{tabular}{lccl}
\hline Choline SNR & $\begin{array}{c}\text { Benign } \\
\text { breast lesions }\end{array}$ & $\begin{array}{c}\text { Malignant } \\
\text { breast lesions }\end{array}$ & \\
\hline Value & $1.902 \pm 0.47$ & $6.31 \pm 0.99$ & $\begin{array}{l}t=23.8 \\
p<0.001 *\end{array}$ \\
Mean \pm SD & & & \\
\hline
\end{tabular}

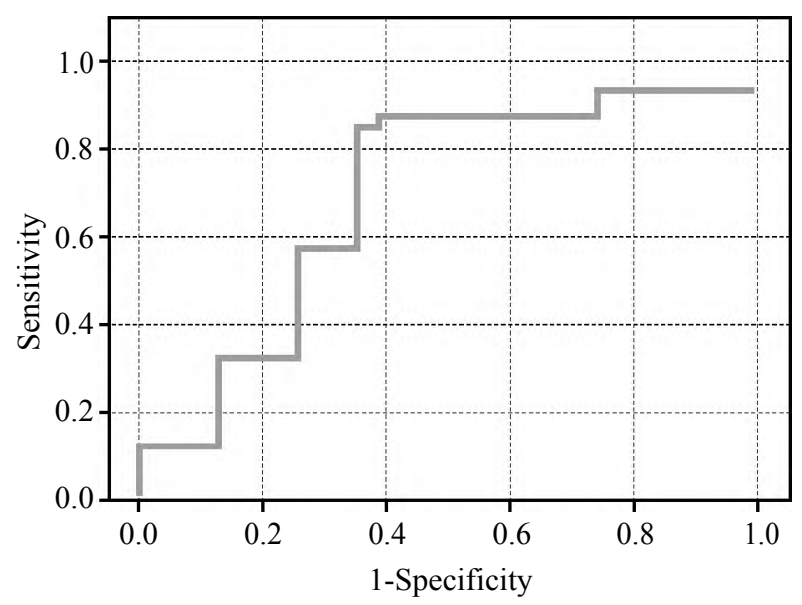

Fig. (1): Showing ROC curve for choline SNR values.

Table (6): Showing the validity of DCE-MRI and choline SNR in differentiating between benign and malignant breast lesions.

\begin{tabular}{lccccc}
\hline & $\begin{array}{c}\text { Sensi- } \\
\text { tivity }\end{array}$ & $\begin{array}{c}\text { Speci- } \\
\text { ficity }\end{array}$ & PPV & NPV & Accuracy \\
\hline - DCE-MRI & $81.3 \%$ & $62.6 \%$ & $76.5 \%$ & $67.1 \%$ & $73.4 \%$ \\
- Combination & $87.9 \%$ & $89.1 \%$ & $85.2 \%$ & $88.9 \%$ & $94.8 \%$ \\
between & & & & & \\
$\begin{array}{l}\text { DCE-MRI } \\
\text { and MRS }\end{array}$ & & & & & \\
\hline
\end{tabular}

\begin{tabular}{ll}
\hline SN : Sensitivity. & PPV : Positive Predictive Value. \\
SP : Specificity. & NPV : Negative Predictive Value
\end{tabular}



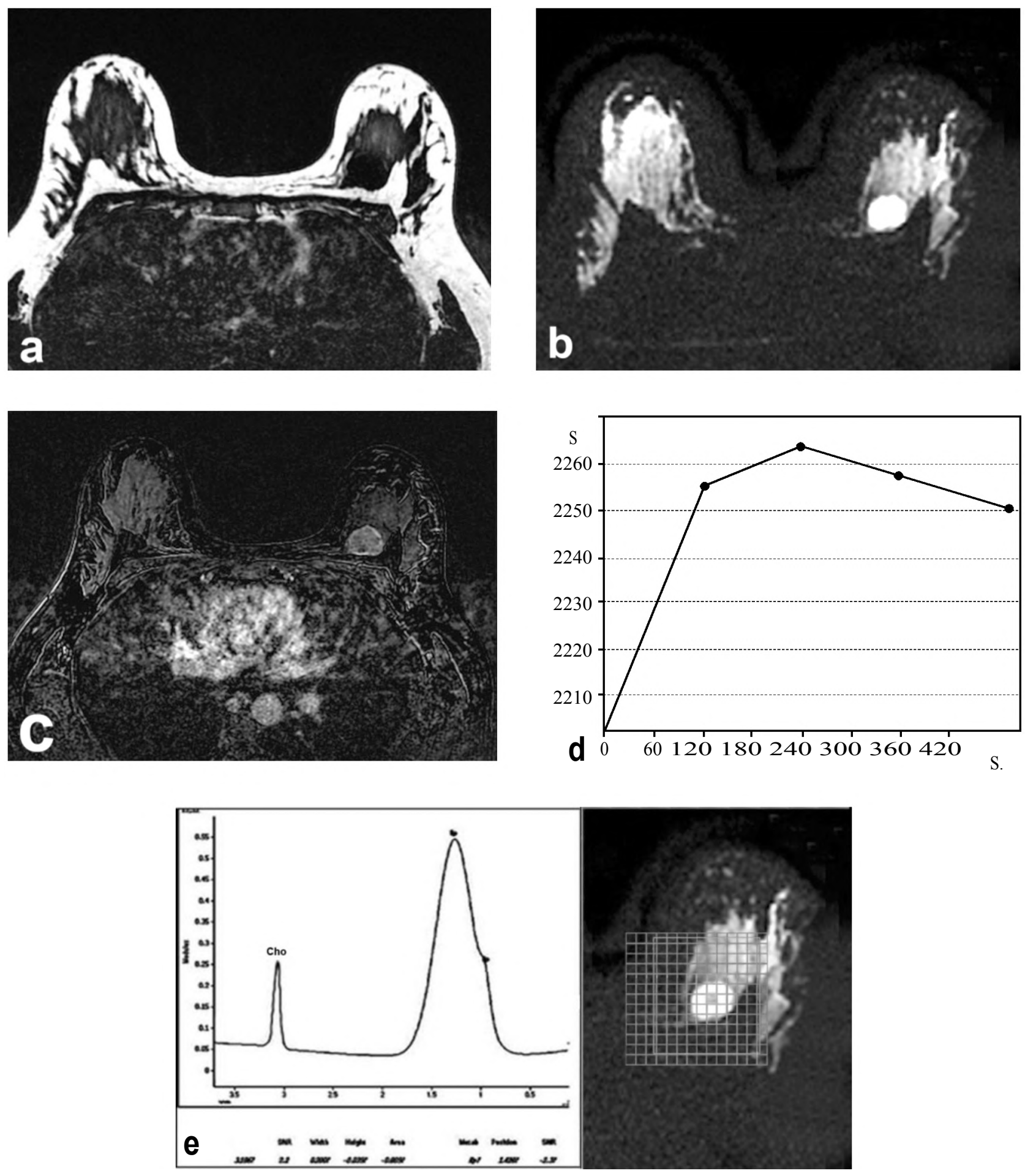

Fig. (2): 44 years-old woman with infiltrating duct carcinoma in the left breast, by DCE-MRI the lesion was categorized as BIRADS 4, then after MRS it was upgraded into BIRADS 5:

A- Pre-contrast T1 weighted axial image showing lobulated lesion seen in upper inner quadrant of the left breast displaying low signal intensity.

B- STIR axial image of the lesion showing high signal intensity.

C- Post-contrast subtraction axial image showing heterogeneous enhancement of the lesion.

D- The enhancement kinetic curve of the lesion is type III washout curve.

E- MRS revealed positive choline peak with $\mathrm{SNR}=2.2$. 

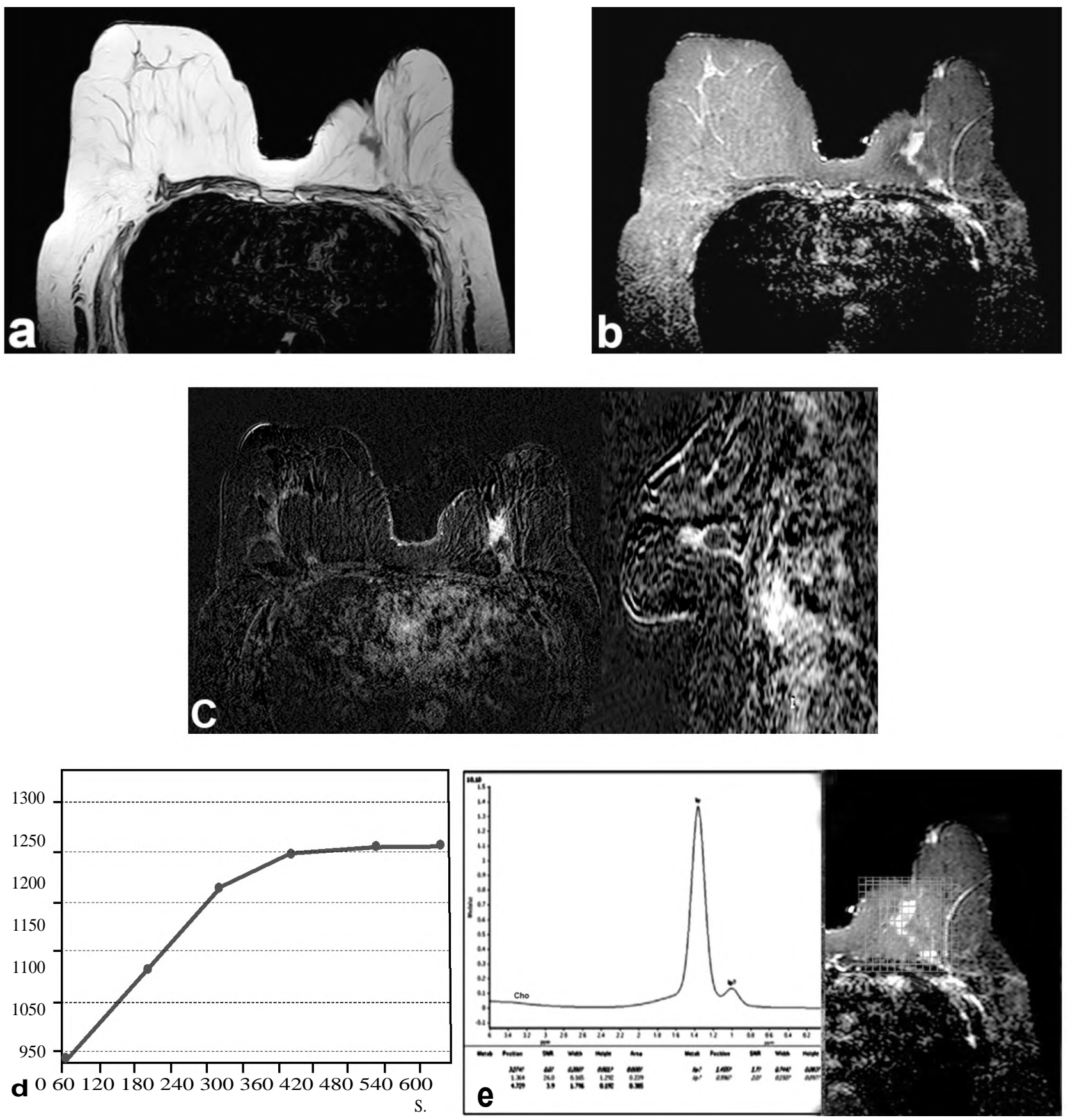

Fig. (3): 57 years-old woman with post conservative surgery changes in the left breast in the form of post-operative fibrosis and scaring mixed with foci of traumatic fat necrosis, by DCE-MRI the lesion was categorized as BIRADS 4, then after MRS it was downgraded into BIRADS 3:

A- Pre-contrast T1 weighted axial image showing the mixed low and high SI of the lesion underlying the post-operative scar.

B- STIR axial image of the lesion showing mixed low and high signal intensity.

C- Post-contrast subtraction axial and sagittal images showing heterogeneous enhancement of the lesion.

D- The enhancement kinetic curve of the lesion is type II plateau curve.

E- MRS revealed negative choline peak. 

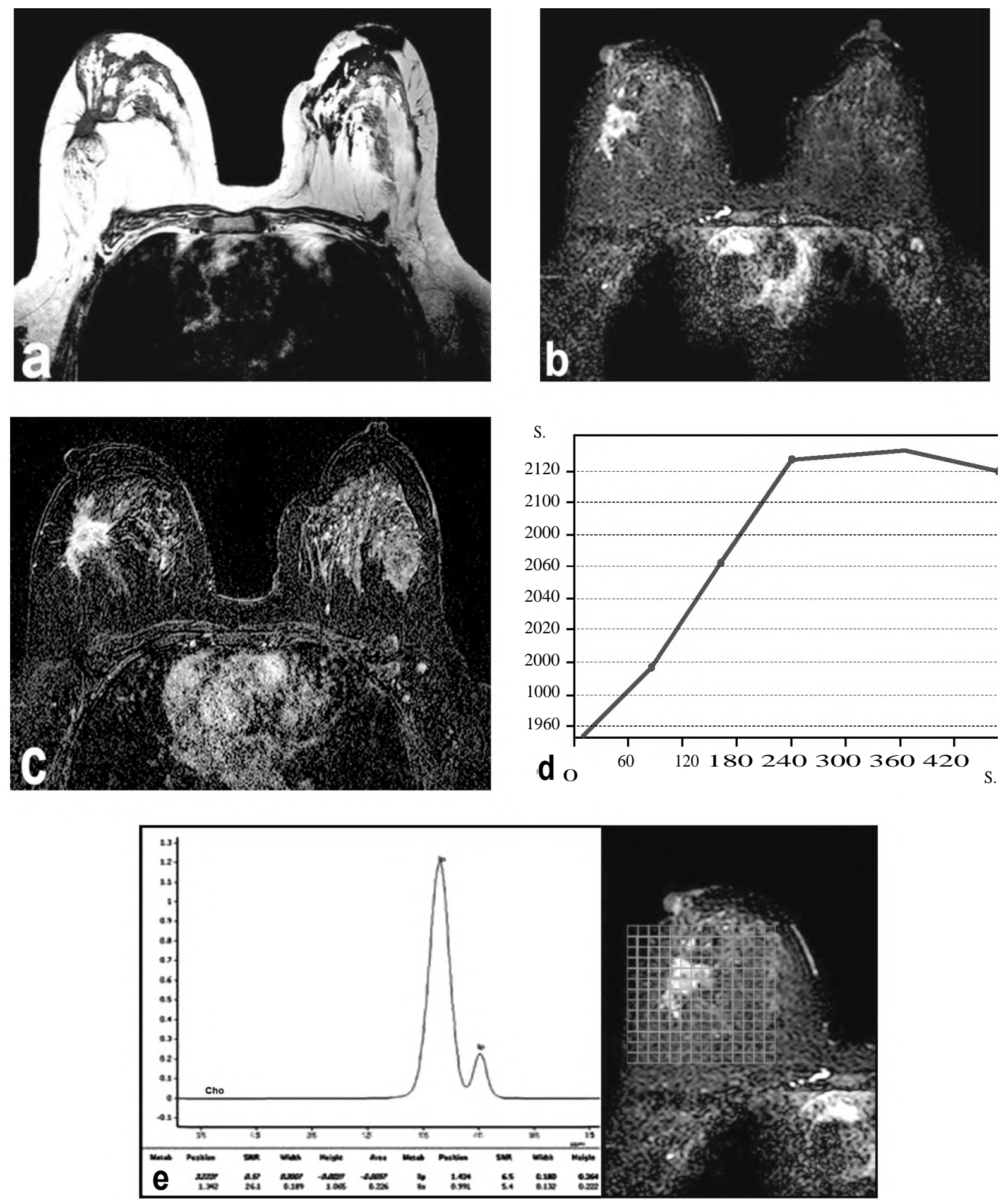

Fig. (4): 59 years-old woman with sclerosing adenosis of the right breast by DCE-MRI and by MRS the lesion was categorized as BIRADS 4:

A- Pre-contrast T1 weighted axial image showing the low SI of the lesion.

B- STIR axial image of the lesion showing high signal intensity.

C- Post-contrast subtraction axial image showing heterogeneous enhancement of the lesion.

D- The enhancement kinetic curve of the lesion is type II plateau curve.

E- MRS revealed negative choline peak. 

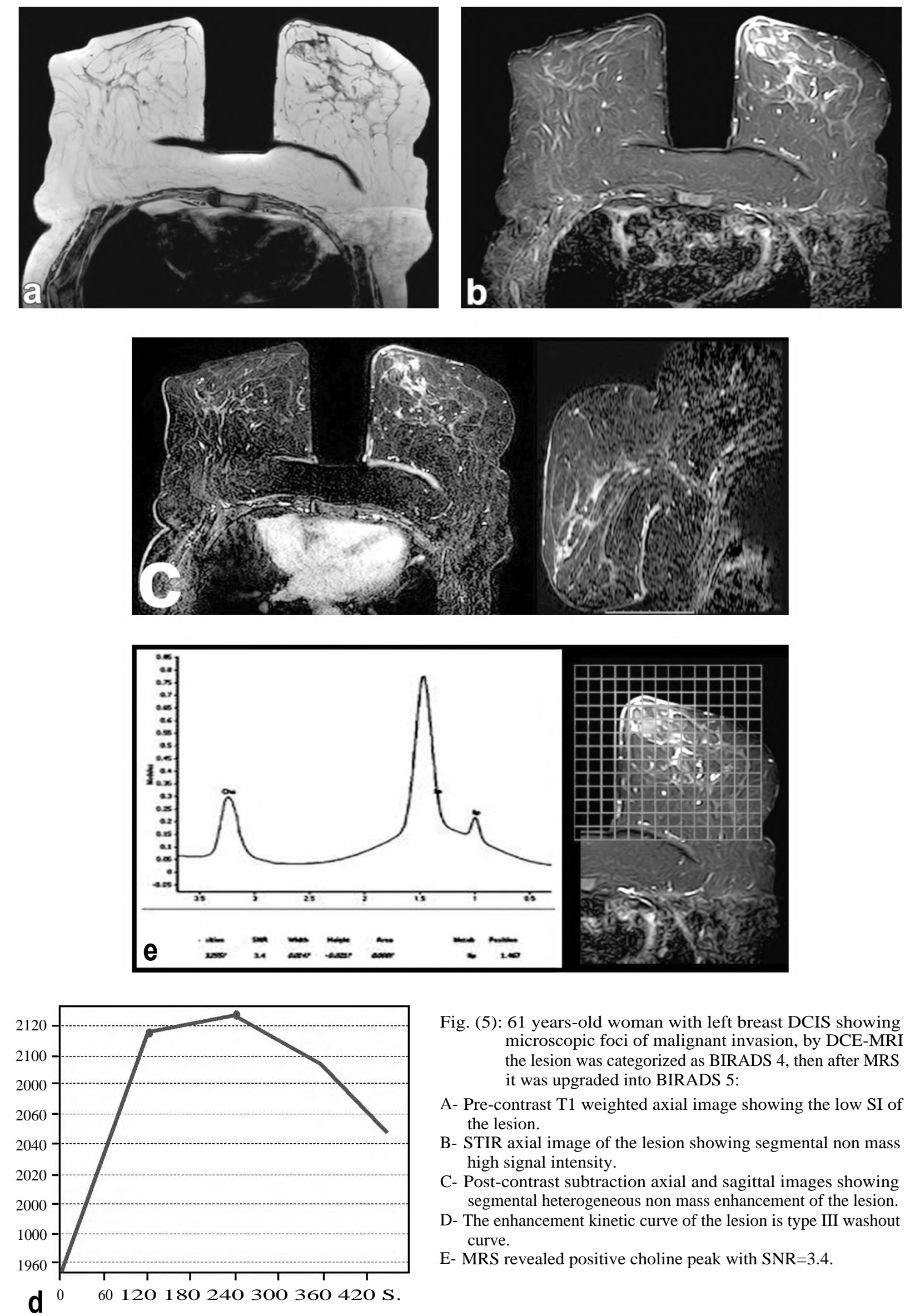

Fig. (5): 61 years-old woman with left breast DCIS showing microscopic foci of malignant invasion, by DCE-MRI the lesion was categorized as BIRADS 4, then after MRS it was upgraded into BIRADS 5:

A- Pre-contrast T1 weighted axial image showing the low SI of the lesion.

B- STIR axial image of the lesion showing segmental non mass high signal intensity.

C- Post-contrast subtraction axial and sagittal images showing segmental heterogeneous non mass enhancement of the lesion.

D- The enhancement kinetic curve of the lesion is type III washout curve.

E- MRS revealed positive choline peak with $\mathrm{SNR}=3.4$. 


\section{Discussion}

Breast cancer is the second leading cause of death in females worldwide; it affects 1 of each 8 women in America. However, breast cancer mortality showed significant reduction over the past several years, due to the earlier-stage breast cancer diagnosis as well as the improved imaging techniques and improved therapeutics planes [7].

Dynamic Contrast-Enhanced Magnetic Resonance Imaging (DCE-MRI) became a widely used method for characterization of breast lesions as it has many uses which include high-risk group screening, evaluation of the extent of breast cancer prior to surgery, screening of the breast in the presence of suspicious axillary lymphadenopathy and evaluation of breast cancer response to neoadjuvant chemotherapy. One of the most common indications of breast MRI is the evaluation of equivocal findings on standard imaging methods, in this case the MRI serves as an important problem solving tool to reach the proper diagnosis [8].

The advantage of Dynamic Contrast-Enhanced Magnetic Resonance Imaging (DCE-MRI) is its high sensitivity (that may reach up to $100 \%$ ) for breast cancer detection comparing to other imaging modality [9]. However it has a relatively lower specificity because of the overlap in the imaging findings between benign and malignant breast lesions with large variations in the PPVs of breast magnetic resonance imaging reported in the literature $(24 \%-89 \%)$ [8,10]

In the current study we had 63 breast lesions all of them were initially categorized as BIRADS 4 lesions on the basis of Dynamic ContrastEnhanced Magnetic Resonance Imaging (DCEMRI). Elverici et al., 2015 [11] defined BIRADS 4 breast lesions as the lesions that do not have the classic picture of malignancy, but are sufficiently suspicious to validate a recommendation for biopsy with still present risk of malignancy.

Leithner et al., 2018 [12] and Marino et al., 2018 [13] reported that the PPV of Dynamic ContrastEnhanced Magnetic Resonance Imaging (DCEMRI) range reach up to $79 \%$. In our study we found that, the overall PPV for malignancy in BIRADS 4 category using Dynamic ContrastEnhanced Magnetic Resonance Imaging (DCEMRI) was $(76.5 \%)$ and that most lesions categorized as BIRADS 4 category did not match the classic appearance of malignancy.

Elverici et al., 2015 [11] also reported that the difference in calculation the PPVs of breast lesions categorized as BIRADS 4 vary over a wide range, probably as a result of the differences in the prevalence of breast cancer and the patient selection criteria.

In this study we tried also to evaluate the role of multi-voxel MR spectroscopy in the recategorization of BIRADS 4 breast lesions which have equivocal criteria on Dynamic Contrast-Enhanced Magnetic Resonance Imaging (DCE-MRI) to improve the diagnostic accuracy of MRI and to reduce the un-needed negative biopsy rates.

MRS spectral data can be evaluated either qualitatively or quantitatively to differentiate between variable tissues such as normal, benign, malignant, necrotic, or even hypoxic tissues. To differentiate benign from malignant lesions the qualitative assessment of the distinct resonance peak of choline peak is done at 3.23ppm to represent malignancy. This technique has demonstrated a sensitivity of $50 \%$ to $100 \%$ and a reported specificity of $61 \%$ to $100 \%$ [14,15].

Choline is one of the cellular metabolites involved in cell membrane synthesis and turnover. It is considered a marker for cellular proliferation and multiplication. The elevated choline peak is observed in vivo at $3.23 \mathrm{ppm}$ and it is elevated in most of the malignant tumors. It actually represents a complex of several different choline-containing compounds (which are: Free choline, phosphocholine, and glycero-phospho-choline) and it is typically referred to as the total choline (tCho) [16]. Although the underlying biological process is still unknown, the elevated choline peak in malignant tumors is thought to be a result from elevated intracellular phospho-choline produced during cell proliferation [17].

Our study is in agreement with Yeung et al., 2011 [14] and Fardanesh et al., 2019 [1] as they reported that the increased levels of the choline can be used as a biomarker to differentiate between benign and malignant lesions. In all our pathologically proven malignant lesions we had positive choline peak at $3.23 \mathrm{ppm}$. Also the choline peak was negative in all the pathologically proven benign lesions.

Bolan, 2013 [18] reported that numerous MRS quantitative markers have been used as promising imaging biomarkers in combination with DCEMRI. The tCho SNR is one of the most reliably used quantitative biomarker till now and it represents the automatically calculated ratio of the choline peak to the amplitude of noise. 
In this study we investigated the role of ${ }^{1} \mathrm{H}$ MRS as an important co-factor to increase breast MRI specificity and there was a statistically significant differences between the Cho SNR of benign and malignant lesions as the Cho SNR in malignant lesions was significantly elevated when compared to benign lesions $(p<0.001)$. In our study we had 63 lesions classified as BIRADS 4 breast lesions, after combining the results of MRS to DCE-MRI, 28 cases were upgraded into BIRADS 5 category as they showed positive choline peak and the choline SNR measured above 2 in all of them. These cases were pathologically proven malignant on histopathological evaluation. These cases were 9 cases diagnosed as ductal carcinoma in situ, 16 cases diagnosed as invasive ductal carcinoma and 3 cases diagnosed as invasive lobular carcinoma.

And we had 29 cases that showed either negative choline peak or choline SNR less than 2, all of these cases were pathologically proven benign breast lesions. 15 cases diagnosed as fibroadenoma, 4 cases diagnosed as Fibroadenosis with apocrine metaplasia, 7 cases diagnosed as post-operative changes, 2 cases of inflammatory hyperplasia without atypia and 1 case of granulomatous mastitis.

We also had Also 6 cases with equivocal criteria by MRS and by DCE-MRI, 4 of them were pathologically proven benign breast lesions (a case of Fibroadenosis with apocrine metaplasia, a case of granulomatous mastitis, a case of sclerosing adenosis and a case of complex fibroadenoma), and 2 pathologically proven malignant lesions ( 1 case of mucinous carcinoma and 1 case of local tumor recurrence).

As regards the cut-off value of cho SNR to differentiate benign from malignant breast lesions, our study is in agreement with other studies such as Beak, 2012 [19], Hancu et al., 2012 [20] and Pinker, et al., 2014 [21], these studies reported that the cho SNR of 2 showed the highest sensitivity and specificity for proper characterization of breast lesions. So the MRS results were considered positive when SNR was greater than or equal to 2 and was considered negative if SNR measured less than 2 . This method has a sensitivity of $44-100 \%$ and specificity of $67-100 \%$. All of these studies are in accordance with the current study, when we used choline SNR of 2 as a cutoff value between benign \& malignant lesions, then we calculated sensitivity $=87.9 \%$, specificity $=89.1 \%, \mathrm{PPV}=85.2 \%$, $\mathrm{NPV}=88.9 \%$, and accuracy $94.8 \%(p<0.001)$.

\section{Conclusion:}

MRS is a promising non-invasive radiological technique that gives important information about the metabolic activity of different tissues. MRS can reliably differentiate between benign and malignant breast lesions, so it is considered as problem solving especially during the evaluation of BIRADS 4 breast lesions when combined with DCE-MRI to improve the diagnostic accuracy and to reduce negative biopsy rates.

\section{References}

1- FARDANESH R., MARINO M.A., AVENDANO D., LEITHNER D., PINKER K. and THAKUR S.B.: Proton MR spectroscopy in the breast: Technical innovations and clinical applications. Journal of Magnetic Resonance Imaging, 2019.

2- BALTZER P.A., KAPETAS P., MARINO M.A. and CLAUSER P.: New diagnostic tools for breast cancer. Memo-Magazine of European Medical Oncology, 10 (3): 175-80, 2017.

3- MARINO M. A., HELBICH T., BALTZER P. and PINKER-DOMENIG K.: Multiparametric MRI of the breast: A review. Journal of Magnetic Resonance Imaging, 47 (2), 301-15, 2018.

4- DORRIUS M.D., PIJNAPPEL R.M., JANSEN-VAN DER WEIDE, M.C., JANSEN L., KAPPERT P., OUDKERK M. and SIJENS P.E.: Determination of choline concentration in breast lesions: Quantitative multivoxel proton MR spectroscopy as a promising noninvasive assessment tool to exclude benign lesions. Radiology, 259 (3): 695-703, 2011.

5- SIJENS P.E., DORRIUS M.D., KAPPERT P., BARON P., PIJNAPPEL R.M. and OUDKERK M.: Quantitative multivoxel proton chemical shift imaging of the breast. Magnetic resonance imaging, 28 (3): 3 14-9, 2010.

6- BAEK H.M., CHEN J.H., YU H.J., MEHTA R., NALCIOGLU O. and SU M.Y.: Detection of choline signal in human breast lesions with chemical-shift imaging. Journal of Magnetic Resonance Imaging: An Official Journal of the International Society for Magnetic Resonance in Medicine, 27 (5): 1114-21, 2008.

7- SIEGEL R.L., MILLER K.D. and JEMAL A.: Cancer statistics, 2015. CA: A cancer Journal for Clinicians, 65 (1): 5-29, 2015.

8- RAHBAR H. and PARTRIDGE S.C.: Multiparametric MR imaging of breast cancer. Magnetic Resonance Imaging Clinics, 24 (1): 223-38, 2016.

9- MAINIERO M.B., LOURENCO A., MAHONEY M.C., NEWELL M.S., BAILEY L., BARKE L.D. and JOKICH P.M.: ACR appropriateness criteria breast cancer screening. Journal of the American College of Radiology, 13 (11): R45-R49, 2016.

10- ELMORE J.G., ARMSTRONG K., LEHMAN C.D. and FLETCHER S.W.: Screening for breast cancer. Jama, 293 (10): 1245-56, 2005.

11- ELVERICI E., BARÇA A.N., AKTAsS H., ÖZSOY A., ZENGIN B., ÇAVU, SO־ GLU M. and ARAZ L.: Nonpalpable BI-RADS 4 breast lesions: Sonographic findings 
and pathology correlation. Diagnostic and Interventional Radiology, 21 (3): 189, 2015.

12-LEITHNER D., MOY L., MORRIS E.A., MARINO M.A., HELBICH T.H. and PINKER K.: Abbreviated MRI of the breast: Does it provide value? Journal of Magnetic Resonance Imaging, 2018.

13- MARINO M.A., HELBICH T., BALTZER P. and PINKER-DOMENIG K.: Multiparametric MRI of the breast: A review. Journal of Magnetic Resonance Imaging, 47 (2): 301-15, 2018.

14- YEUNG D.K., CHEUNG H.S. and TSE G.M.: Human breast lesions: Characterization with contrast-enhanced in vivo proton MR spectroscopy-initial results. Radiology, 220 (1): 40-6, 2001.

15- BEGLEY J.K., REDPATH T.W., BOLAN P.J. and GILBERT F.J.: In vivo proton magnetic resonance spectroscopy of breast cancer: A review of the literature. Breast Cancer Research, 14 (2): 207, 2012.

16- BALTZER P.A. and DIETZEL M.: Breast lesions: Diagnosis by using proton MR spectroscopy at 1.5 and $3.0 \mathrm{~T}$ systematic review and meta-analysis. Radiology, 267 (3): 735-46, 2013
17- BARTELLA L., MORRIS E.A., DERSHAW D.D. LIBERMAN L., THAKUR S.B., MOSKOWITZ C. and HUANG W.: Proton MR spectroscopy with choline peak as malignancy marker improves positive predictive value for breast cancer diagnosis: Preliminary study. Radiology, 239 (3): 686-92, 2006.

18- BOLAN P.J.: Magnetic resonance spectroscopy of the breast: Current status. Magnetic Resonance Imaging Clinics, 21 (3): 625-39, 2013.

19- BAEK H.M.: Diagnostic value of breast proton magnetic resonance spectroscopy at $1.5 \mathrm{~T}$ in different histopathological types. The Scientific World Journal, 2012.

20- HANCU I., GOVENKAR A., LENKINSKI R.E. and LEE S.K.: On shimming approaches in 3 T breast MRI. Magnetic resonance in medicine, 69 (3): 862-7, 2013.

21- PINKER K., BOGNER W., BALTZER P., GRUBER S., BICKEL H., BRUECK B. and BARTSCH R.: Improved diagnostic accuracy with multiparametric magnetic resonance imaging of the breast using dynamic contrastenhanced magnetic resonance imaging, diffusion-weighted imaging, and 3-dimensional proton magnetic resonance spectroscopic imaging. Investigative radiology, 49 (6): 421-30, 2014.

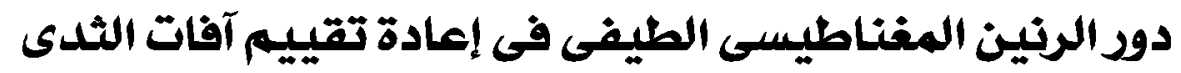

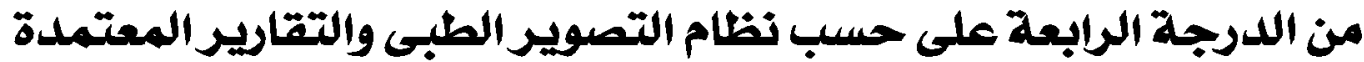

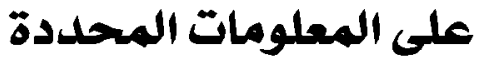

\author{
يعتبر مرض سرطان الثى من آكثر الآودام إنتشاراً فى العالم وآيضاً يعتبر من آكثر آسباب الوفيات بين النساء. ولذلك هناك الكثير من

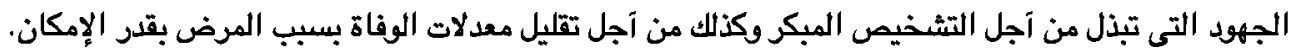 \\ توجد الكثير من فحوصات الآشعة التى تساعد فى التشخيص المبكر مثل الماموجرام والسونار وكذلك الرنين المغناطيسى، ولكن يتميز

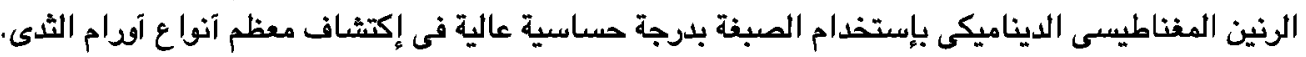 \\ يعتبر الرنين المغناطيسى الطيفى واحد من آنواع فحوصات الرنين المغناطيسى التى لا تحتاج إلى حقن صبغة معينة وهذا الفحص يقوم

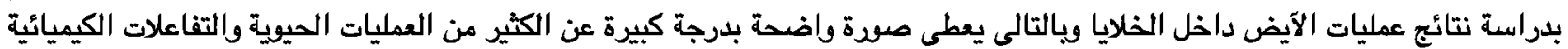

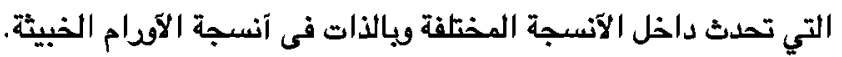 \\ ويعتبر مركب الكولين واحد من آهم المركبات التى يتم دراستها فى فحص الرنين المغناطيسى الطيفى ويزداد تركيز الكولين بدرجات التيات كبيرة

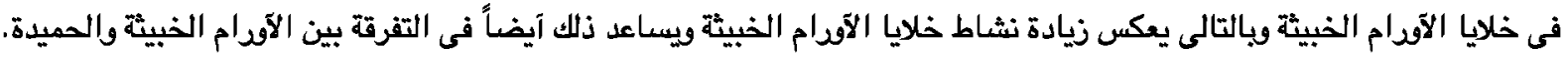 \\ الهدف من البحث: دراسة دود الرنين المغناطيسى الطيفى فى إعادة تقييم آفات الثىى من الدرجة الرابعة على حسب نظام التصوير الطبى

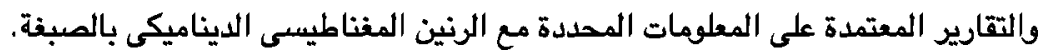

